\title{
Expert opinion
}

\section{Private in-patient psychiatric care}

\author{
MARKS, I. \& ThORNICROFT, G. (1990) British Medical Journal (editorial), 300, 892
}

A recent leading article on Private In-patient Psychiatric Care by Isaac Marks \& Graham Thornicroft (1990) generated a flurry of indignant responses from colleagues working in the private sector (White et al, 1990). So far as I could tell, the leader contained neither factual errors nor rash statements yet such discussions always generate an emotive response.

I am committed to the concept of a health care system, available to all regardless of ability to pay and providing comprehensive continuous, effective, humane and continuous care to all of those in need. At the same time I am convinced that no society has the resources to provide care on demand without some form of rationing, of which ability to pay is one.

Another approach to rationing is demand limitation. In Britain an effective mechanism for achieving this has been the general practitioner or primary care service which provides the filters so elegantly described by Goldberg \& Huxley (1980). In the general population about 250 per 1,000 have some detectable psychiatric morbidity, some 230 attend the general practitioner of whom 140 are recognised as having conspicuous psychiatric morbidity. Only 17 reach the psychiatric services and six become in-patients.

The correlations between 'seriousness' or 'severity' and psychiatric referral are far from perfect but those presenting disruptive behaviour are at risk of harm to themselves or others are likely to be hospitalised.

Although those filters are evidently effective the care which the emotionally disturbed receive in general practice is not a matter for congratulation. Much psychiatric morbidity is unrecognised by the general practitioner and often unacknowledged by the patient.

Many individuals with psychiatric symptomatology can be.designated as attention-seeking but help-rejecting. They have a high rate of consultation and psychotropic drug use but are frequently unwilling to accept appropriate treatment or referral.

Increased sensitivity and better training of GPs and greater support by community psychiatric teams might well improve the quality of psychiatric care in general practice without increasing the specialist re- ferral or admission rates. However, one of the major differences between the United States and Britain at present is the ready availability of admission for acute psychiatric disorder. In many parts of the United States only the criminal or dangerously insane can be admitted to the State Hospital, a factor which undoubtedly contributes to their traumatic de-institutionalisation problems.

One of the major advances of health care in my time has been the acceptance of the epidemiological concepts of service to communities rather than exclusively to individuals. Although Dr White (1990) believes that the catchment area concept originated in the wish of individuals or institutions to exclude unwelcome patients, its effect has been to clearly allocate the responsibility for comprehensive sector care. It also serves to ration scarce resources by reducing the possibility of multiple referral or of simultaneous and unrelated care plans.

The quality of psychiatric care has been limited by inadequate manpower establishments, poor quality staff and training and overburdened, often shoddy in-patient services.

A comprehensive psychiatric team is not only better able to provide adequate care but should provide it most economically yet professional identity struggles have fragmented the team so that nurses, psychologists, rehabilitation staff and psychiatrists are in competition rather than partnership.

The rigidity of employment patterns with inflexible gradings and bureaucratic job descriptions encourage boundary disputes and prevent flexible and appropriate care patterns. Although the mental health services have been grossly underfunded both since the introduction of the NHS and before, we could make better use of the inadequate funds available if we had greater freedom.

Doctrinaire views by the parties in government have adversely effected psychiatric care. Neither has given mental health its due priority. Labour's refusal to countenance private practice and discouragement of amenity facilities within the NHS has robbed us of much needed funds. The equally rigid market economy of the Conservatives has proved even more damaging. 
Treasury-inspired moves towards community care could disrupt such psychiatric services as we have if they involve further splitting of the psychiatric professions and severe reduction of acute psychiatric admission facilities.

Where can private practice help in this mess? We have had some good models for consultant-only service patterns, the development of specialised services not currently available in the NHS such as units for the young brain damaged and enviable physical provisions for in-patient services.

Except in providing an unattainable standard to aspire to, I cannot see where private psychiatric consultation, treatment or hospitalisation has made a significant contribution to the health care of the larger community. It is unattainable because it costs too much in money and human resources.

I would prefer a service in which appointments are quickly given, always kept by a named consultant and sufficiently unhurried as to facilitate human courtesies and adequate time for proper assessment and treatment. If you can afford to pay the going rate for that, you are better off than the vast majority of the populace. They must go to a consultant whose sector service is not the 40,000 recommended by the College years ago but still today may be 70,000 or even 100,000 souls whose psychiatric needs are expected to be fully met within the sector.

The private sector is driven by profit and must carefully cost what it provides. This results in better information and greater flexibility than in the NHS. They provide meetings and training as part of their education effort but that too is costed. Their meetings are cost effective both in improving their acceptability and in generating referrals. Their training is of trainees who contribute to the running of the private service and whose 'free' contribution to NHS service are a means of improving recruitment and securing recognition.

There is considerable scope for contracting out the residential care of many elderly mentally infirm and some of the chronic mentally ill. To a lesser extent some specialised services may be contracted out within the NHS or to the private sector.

Perhaps one of the private companies would care to contract with a health authority to provide comprehensive care within their district. I suspect that some economies would be achieved with their greater flexibility but I believe that their standards would inevitably fall.

Cooperation should never be rejected out of hand but the costs must be examined. At present the private sector draws from the community doctors and nurses trained at public expense and who are in short supply within the public sector. Any further expansion of the private sector should only be encouraged if the cost-benefit equation is clearly in the interests of the larger community.

\section{References}

Goldberg, D. \& HuXLey, P. (1980) Mental Illness in the Community. The Pathway to Psychiatric Care. London: Tavistock Publications.

Marks, I. \& ThoRnicroft, G. (1990) Private inpatient psychiatric care. British Medical Journal, 300, 892.

WhITE, A. C. et al (1990) Private inpatient psychiatric care. British Medical Journal, 300, 1136-1137.

Professor of Psychiatry,

SYDNEY BRANDON

University of Leicester School of Medicine.

Leicester Royal Infirmary, P065, Leicester LE2 7LX

This editorial article alleges certain deficiencies in private psychiatry which can be immediately admitted. Firstly, private psychiatry is not comprehensive and is not geographically evenly distributed. There are restrictions on certain chronic conditions. In general, private medicine is orientated towards efforts to cure particular episodes of illness rather than the very long-term support that some severely damaged patients may need, which of course, the NHS ought to provide. The editorial says that there are no adequate follow-up studies in private medicine comparing the level of clinical improvement with that available in the NHS. This is true, but the editorial goes on to say that similar data for the NHS are on the whole conspicuous for their absence. The editorial says correctly that private medicine has not been given overall planning responsibility for comprehensive care. I, for one, would hope that it is not given this responsibility which it is not set up to take on. Whether or not deregulation led to poorer standards of care in America, there is no reason to suggest automatically that Great Britain might follow the same path. The fact that the private sector looks for potentially profitable gaps for which the NHS does not provide adequately does not mean that standards will necessarily be poor. The services, for instance, for brain damaged or for behaviour disordered people in Northampton, or the sheltered workshop and the in-patient psychotherapy unit at Cheadle Royal, show that the private sector can innovate and can in some ways clinically surpass what the NHS can manage. The fact that long-term patients, who may be adequately financed, may not be welcomed does not lower the standard for others. Who, after all, is satisfied with the way in which the long-term damaged have been pushed out over many years of British psychiatric hospitals into inadequately provided facilities in the community?

The objection that the private sector provides a different tier of service seems to be political rather than medical. Who says that the existence of Eton and Harrow and Oxford and Cambridge harm local 
schools and local universities? Who suggests that the existence of Harrods and Fortnum and Masons selling luxury foods damages local retail food supermarkets? The political climate for the last 12 years has been in favour of alternate provision in housing, education and medicine and this is most unlikely to be dismantled.

Private psychiatry is considered to be a cause for anxiety because its existence might threaten the catchment area concept. In general, this concept was and is valuable because it means that responsibility for difficult patients cannot be shrugged off, and because it means that district planning is mandatory. Nevertheless, it would be idle to pretend that the catchment area concept satisfies everyone and that therefore competition should excite disapproval. Many patients, GPs and psychiatrists hate the consequences of rigid sectorisation.

The most unreasonable criticism, however, is the idea that the private market may offer "perverse incentives to deliver excessive or inappropriate services". Here, the authors should have quoted chapter and verse. They should have indicated excesses where private psychiatry had been guilty in this country. I would be surprised if they could point to many such instances.

There are, of course, difficulties in private hospitals which the authors do not mention. It is often difficult to find enough nurses and occupational therapists precisely because the private sector does not, contrary to what its accusers say, pay very large premiums over the NHS to recruit staff. Most patients like the speed with which decisions can be made immediately by the consultants they have selected, but sometimes doctors cannot be available because of their NHS commitments. The situation is better than in private surgical hospitals because at least private psychiatric hospitals require staff consultants both for milieu purposes and for possible compulsory detention. These staff consultants can be available for emergencies. The private sector, however, in general medicine as well as in psychiatry is in difficulty because there is no adequate registrar tier. It would be helpful if those in Royal Colleges responsible for training recognise the diversity and difficulty of the work that private hospitals undertake. There could then be a negotiation so that doctors in training could also help in private hospitals, in particular with the emergency work. If the attitudes of Marks \& Thornicroft are typical then the development of a larger, more diverse, really efficient private sector will be that much impeded. The authors are right, however, that such development will not be held back precisely because patients want it and are prepared to pay.

MichaEl J. TARSH

Consultant in Charge, Bowden House Clinic, Harrow HA1 3JL, formerly Consultant Psychiatrist, Salford Health Authority
In a leader article in the British Medical Journal, under this title the authors, Marks \& Thornicroft (1990), in their first sentence, sought immediately to separate out and to focus on the for-profit sector. Such a tactic in a polemical article on psychiatric care is by analogy tantamount to separating out the Maudsley Hospital from the generality of National Health Service hospitals in an article on public inpatient psychiatric care. Better by far that we psychiatrists give consideration to as many of the issues as possible concerning the provision of in-patient psychiatric care in general and the provision of private in-patient psychiatric care in particular.

Three significant events within the National Health Service deserve reflection. First the rapid reduction in the number of psychiatric beds in the National Health Service in England and the inadequacy of those beds remaining to provide and cater adequately for the seriously mentally ill (Thornicroft \& Bebbington, 1989). Second, the trend in National Health Service psychiatric services to develop niches for discrete patient care, determined by a number of factors such as age, diagnosis, legal status, 'treatability', acceptability to the clinical team, and other random determinants for admission or refusal of admission. Third, the significant change in 1980 to National Health Service Terms and Conditions of Service for Medical Staff whereby all consultants are entitled to engage in private practice. As a consequence, and not unnaturally, given the current concept of continuity of care in psychiatric practice, consultants want private in-patient facilities to which they have ready access and which are generally unavailable in the National Health Service.

The British Medical Journal leader properly, and as accurately as possible, described the growth of private psychiatric hospital beds and hospitals but mentioned in passing reference only the long tradition in the United Kingdom of the independent private and charitable hospitals exemplified today by the Retreat Hospital, York, founded in 1792, the Cheadle Royal Hospital, Cheshire, founded in 1763 and St Andrew's Hospital, Northampton, founded in 1838. The history of these hospitals (Digby, 1985; Foss \& Trick, 1989; Roberts, 1967) and their current operations, as detailed in their tradition of annual reports, portray the diversity and success of their past and current operations. Private in-patient psychiatric care benefits many more patients and families than implied in the leader.

In detailing the growth of private health insurance, the holders of which represent about $40 \%$ only of current in-patients in private in-patient psychiatric care, the British Medical Journal leader failed however to criticise the irrationality of the practice of discrimination by private health insurance companies against psychiatric illness and health problems of substance abuse, including alcohol-related problems. 
A loud and clamant complaint is needed from psychiatrists, similar to, and of the same order as, the constant and clamant complaints about discrimination against the impoverishment of and discrimination against psychiatric care in the National Health Service. We must struggle on in all quarters to promote mental health as an essential component of health (WHO, 1979).

There is no justification whatsoever on known facts at present to use trends in the USA to disparage and offer critical predictions of private in-patient psychiatric care in the independent sector in the United Kingdom. Indeed under the umbrella of the Independent Health Care Association good quality of care, standards of practice and pursuit of clinical care evaluation are fostered and promoted by the private independent hospitals. These audit activities give opportunity for assessment, adjudication and adjustment of conditions of patient care in addition to ensuring the statutory demands of local registration and inspection authorities.

The impression that patients choose their hospitals is as erroneous in the private sector as it is in the National Health Service. Patients are referred for private in-patient care by general practitioners and consultants since it would be ethically improper otherwise (GMC, 1987). That they choose to refer patients repeatedly and increasingly can be one measure of satisfaction perhaps with the efficacy as well as the efficiency of private care.

While conceding that private care has no overall responsibility for a catchment area in a geographical or demographic sense, the private sector is performing and will continue to perform in response to the many and differing clinical needs of a significant community of persons often with severe mental illness and for whom in-patient care is appropriate. The survival, growth and continuation of the sector will be no more and no less of a two tier system than that prevailing in the National Health Service as exemplified by the teaching and non-teaching hospital dichotomy. Better by far that the private inpatient psychiatric care system presently evolving be welcomed and given propriety by the professions in the National Health Service as well as by those who govern it (Secretaries of State for Health, 1989).

It is appropriate that this response to the British Medical Journal leader is appearing in the Bulletin of the Royal College of Psychiatrists which is as its name implies. It is not a Royal College for National Health Service Psychiatrists only. It is sad to reflect that in the recent past the prejudice, bigotry and discrimination within a section of the membership of the College against private practice in psychiatry have impeded and withheld developments in research and training in psychiatry, happily a situation which is changing (Cobb, 1990).

My thanks go to the many colleagues within the National Health Service and the private sector who contributed their views, comments and opinions to me. Nevertheless the responsibility for the manner and content is entirely my own.

\section{JOHN H. HENDERSON Medical Director St Andrew's Hospital Northampton NN1 5DG}

\section{References}

COBB, J. (1990) Private inpatient psychiatric care. British Medical Journal, 300, 1136-1137.

DigBY, A. (1985) Madness, Morality and Medicine. Oxford University Press.

Foss, A., Trick, K. (1989) St Andrew's Hospital: The First One Hundred and Fifty Years (1838-1988). Cambridge: Granta Editions.

General Medical Council (1987) Professional Conduct and Discipline. London: GMC.

MARKS, I. \& THORNICROFT, G. (1990) Private inpatient psychiatric care. British Medical Journal, 300, 892.

ROBERTS, N. (1967) Cheadle Royal Hospital: A Bi-Centennial History. Altrincham: John Sherrat \& Sons, St Anne's Press.

Secretaries of State for Health, Wales and Northern IRELAND AND SCOTLAND (1989) Working for Patients. London: HMSO (Cmnd 555).

Thornicroft, G. \& BebBington, P. (1989) Deinstitutionalisation - from hospital closure to service department. British Journal of Psychiatry, 155, 739-753.

World Health ORganization (1979) Formulating Strategies for Health for all by the Year 2000. Geneva: WHO. 